\title{
Supplier selection model for a Brazilian oil company based on a multi-criteria group decision approach
}

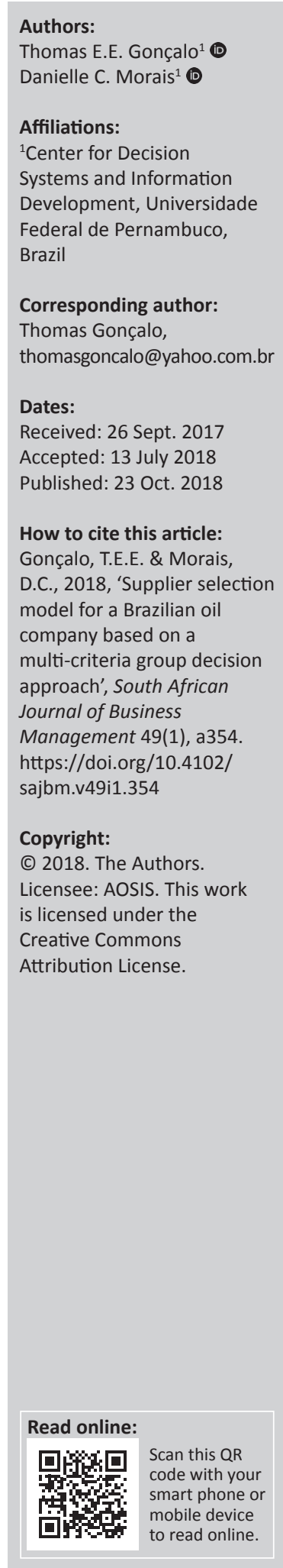

Background: Increasing competition among companies in the oil and gas industry results in a greater need for efficient processes. In Brazil, most oil operations are owned by a single company, which has a public trade structure. The company requires a large number of suppliers, including suppliers of raw materials, equipment and services. In fact, the company needs to employ experts to assist in the supplier selection process in order to be able to choose the best available alternatives. Therefore, supplier selection has been seen to have a significant impact on the success or otherwise of the company's ventures.

Objectives: This article proposes a group decision multi-criteria model for selecting suppliers for a Brazilian oil company.

Method: It is proposed to use the PROMETHEE II method to obtain decision-makers' individual evaluations and the voting procedure by quartiles so as to convert the individual positions into a position for the group.

Results: An application of the model is performed to demonstrate the feasibility of the model in addressing supplier selection problems in a context with multiple stakeholders. Combining the results from the individual analysis of the PROMETHEE II method with the voting by quartiles procedure allowed individual preferences to be aggregated into a result that was representative of the group and produced a ranking of suppliers for one of the type of services used by the company.

Conclusion: The results were very satisfactory, demonstrating that it is possible to apply the model to a context featuring additional decision-makers and alternatives.

\section{Introduction}

Efficiency in companies is an essential requirement in a competitive, globalised environment. In recent years, companies have had to address the challenge of their competitors rapidly becoming as skilled as they are. Good operational performance and the influence of the various stakeholders present in the markets require greater control and a need to increase the efficiency of the activities performed by any company.

In order to make a preliminary assessment of the issues involved, we conducted a review of the literature from which we identified the need to re-assess the following: supplier selection; the need for more robust decision support tools, in particular appropriate voting procedures and a group decision approach; and the need to consider how the oil industry might make use of advances in these matters made by other industries and set out in published research. The following paragraphs give more details about recent research on these issues which are subsequently exploited throughout the rest of this article.

According to Scott et al. (2015:226), given the complexity and length of some supply chains, issues that arise and that involve the stakeholders impacted by supplier selection are complex and varied. To Chai and Ngai (2015:215), suppliers are important to a company because of their roles and influence in supply chains.

According to Ekici (2013:574), most companies procure raw materials from outside suppliers where there are competing suppliers with different capacities, pricing, service and quality levels. Osman and Demirli (2010:97-98) state that increasing the efficiency of the partners in the supply chain becomes the highest priority for any supply chain because of the highly competitive nature of the current global market. Therefore, supplier selection is a crucial issue from both the managerial 
and operational viewpoints because a smart decision benefits a company considerably. To Kefer et al. (2016:1-2), an organisation should establish and apply criteria that will be used to evaluate, select and monitor performance.

As discussed by Liao and Rittscher (2007:150-151) and Vinodh, Ramiya and Gautham (2011:272), the problem of supplier selection is a multi-criteria decision-making problem in the presence of various quantitative or qualitative criteria and sub-criteria. Because of this characteristic, robust tools for decision support must be used and these must be continuously improved. These decisions are becoming increasingly complex as outsourcing and electronic businesses are constantly increasing. To $\mathrm{Wu}$ (2009:8892-8893), when experts with conflicting opinions are involved, the decision to select a supplier becomes a group decision problem. In the context of decision-making support tools in groups, we emphasise voting procedures as being an important alternative for supporting the supplier selection process.

According to Chai, Liu and Ngai (2013:3872-3873), supplier selection has received considerable attention because of its significant effect on the success or otherwise of logistic and supply chain management. To Saen (2007:84-85) and Kahraman, Cebeci and Ulukan (2003:382-383), supplier selection is the process by which suppliers are inspected, evaluated and chosen to eventually become part of the supply chain of an organisation, the purpose of which is to identify suppliers with the greatest potential for consistently meeting the organisation's needs. As presented by Ho, $\mathrm{Xu}$ and Dey (2010:16) and Wu et al. (2010:774), the selection process involves much more than a simple analysis of prices, and the choices depend on a wide range of factors, both quantitative and qualitative. Schramm and Morais (2012:1617) conclude that in the supplier selection process, most managers consider only criteria related to cost and quality, and do not use any formal method that provides an evaluation framework for doing so.

As discussed by Amid, Ghodsypour and O'Brien (2009:323324) and Sarkis and Dhavale (2015:190), complexities arise when multiple suppliers are to be evaluated on an increasing and typically conflicting set of dimensions and the purchasing manager must analyse the trade-offs among the criteria. In the field of decision support tools, multi-criteria approaches are gaining more attention owing to their robustness and abilities to facilitate the analysis of more complex cases. According to Vincke (1992), a multi-criteria decision aid aims to provide the decision-maker (DM) with tools to enable advances in decision troubleshooting during which many, often contradictory, points of view must be taken into consideration.

To Wu (2009:8892-8894), decisions are becoming more complex as outsourcing and electronic business increase. When more experts, and therefore more conflicting opinions are involved, the supplier selection decision becomes a group decision problem. As discussed by Dobos and Vorosmarthy
(2014:273-275), introducing the environmental dimension into purchasing decisions embeds a new set of trade-offs in the decision, thereby complicating the decision-making process with both qualitative and quantitative factors. According to Chen et al. (2016:1-3), although numerous studies have used economic criteria in the supplier selection process, only a limited number of these have considered the economic and environmental criteria simultaneously.

To Chai and Ngai (2015:215-218), supplier selection under the paradigm of MCDM has been widely accepted by academic and industrial communities, which has led to a new era of strategic supplier selection. Chai et al. (2013) analysed MCDM approaches for supplier selection based on articles published in journals from 2008 to 2012. Their analysis showed that a large number of different approaches has been applied, such as multi-attribute decision-making techniques: analytic hierarchy process (AHP), analytic network process (ANP), elimination and choice expressing reality (ELECTRE), preference ranking organisation method for enrichment evaluation (PROMETHEE), technique for order performance by similarity to ideal solution (TOPSIS), multi-criteria optimisation and compromise solution - the acronym comes from the original title which is in Serbian (VIKOR), decision-making trial and evaluation laboratory (DEMATEL) and simple multi-attribute rating technique (SMART); mathematical programming techniques: DEA (data envelopment analysis), linear programming, nonlinear programming, multi-objective programming, goal programming and stochastic programming; and artificial intelligence techniques: genetic algorithm, grey system theory, neural network, rough set theory, Bayesian networks, decision tree, case-based reasoning, particle swarm optimisation, support vector machine, association rule, ant colony algorithm and the Dempster-Shafer theory of evidence.

The complexity of supplier selection in the oil and gas sector is not different. It is a market in constant growth, which requires its processes to be rigorously managed. In Brazil, the sector suffers from intense influence by the government agent. Until 1997 one company had the monopoly on the extraction and refining of petroleum. Even though this monopoly has been broken, this company currently has an important role in the oil and gas sector in Brazil and is a major player in the international market. It is well-known that it is the largest company in Brazil and has been experiencing, from 2014 to the present day, serious credibility problems owing to corruption, cases of which are still under legal investigation. Many of these problems arose from the relationships that the company had with suppliers of certain services, particularly construction companies. These problems include how to avoid the practice of government appointees to senior positions in the company offering contracts to suppliers in exchange for large donations to political parties that support the government. Moreover, when selecting a supplier, the company needs to consider multiple criteria, including technical, financial, social and 
environmental issues, which makes the decision even more complex. Thus, the development of a model for supplier selection in this context appears to be essential. In the light of this very complex environment, the proper management of business processes is crucial to the success of the company.

This study sets out to investigate how the selection of products and service suppliers occurs in a Brazilian oil company and proposes a multi-criteria group decision model to support this process. Therefore, it is proposed to use the PROMETHEE II method to obtain DMs' individual evaluations and the voting procedure by quartiles so as to convert the individual positions into a position for the group. To date, the combination of methodologies has been proposed only in the context of water resource management by Morais and Almeida $(2010 ; 2012)$, this article being the first in which PROMETHEE II and quartiles voting procedure are used to tackle the problem of selecting suppliers.

The organisation of the rest of this article is as follows: In the 'Group decision and voting procedures' section, the background to group decision and voting procedures is presented. In 'The supplier selection process in the company' section, the company under study is characterised and the process of selecting suppliers is described. The 'Proposed group decision model for selecting suppliers for a Brazilian oil company' section presents a model for group decision, and its implementation is discussed in the 'Results and discussion' section. In the final section, the results are discussed and some conclusions are drawn.

\section{Group decision and voting procedures}

To Hatami-Marbini and Tavana (2011:373-374), a group decision problem requires the aggregation of different individual preferences in a set of collective preferences. According to $\mathrm{Wu}$ (2009:8892-8897), one of the key points of the analysis involves the choosing function and aggregation operators to combine the different views of the agents into a single numeric value. The process of supplier selection is a group decision problem with multiple criteria. As presented by Kar (2014:2762), while decision support literature on supplier selection is extensive, the applicability of the theories of group decision support is yet to be explored for the supplier selection problem.

Several authors have proposed models and multi-criteria decision support tools to address group decision-making problems. Scott et al. (2015) proposed an integrated method for dealing with such problems using a combined analytic hierarchy process-quality function deployment (AHP-QFD) and a chance-constrained optimisation algorithm approach that selects appropriate suppliers and allocates orders optimally between them; Hatami-Marbini and Tavana (2011) proposed an alternative fuzzy outranking method by extending the ELECTRE I method to take into account the uncertain, imprecise and linguistic assessments provided by a group of DMs; Sevkli et al. (2008) propose a new approach called an 'analytical hierarchy process weighted fuzzy linear programming model (AHP-FLP)' for supplier selection; $\mathrm{Ku}$, Chang and Ho (2010) propose a study integrating the fuzzy AHP and the fuzzy goal programming (FAHP-FGP) method as a new approach for global supplier selection when considering a manufacturer's supply chain strategies. In Sanayei, Mousavi and Yazdankhah (2010), a hierarchical MCDM model based on fuzzy sets theory and the VIKOR method is proposed to deal with the supplier selection problems in the supply chain system; Bai and Sarkis (2010) expand on a novel approach first introduced by Li, Yamaguchi and Nagai (2008). This approach uses a grey system and rough set theory.

There are several classes of methods to support group decision-making. According to Almeida et al. (2012), there are two types of procedures for group decision-aggregation:

- Aggregation from the DMs' initial preferences, where each DM's final result is not directly viewable, as the aggregation is developed from their initial preference data.

- Aggregation from the $\mathrm{DMs}^{\prime}$ results and final choices, where each DM presents the final outcome of prioritising (selecting or ordering) alternatives as an input to the aggregation process.

Among the second type of procedures, voting procedures are highlighted. A number of group decision-making support procedures involve voting procedures. According to Almeida et al. (2012), voting systems can be used for elections and other purposes. These may support a multi-criteria decision process involving a set of DMs. Sarkis and Dhavale (2015:1214) state that managers and DMs accept tools and models that are easily understood. Thus, voting procedures are important alternatives to multi-criteria methods that support group decisions. Decision-makers understand these tools more easily, and they require less data processing and bring relative transparency to the selection process.

According to Favardin, Lepelley and Serais (2002:213-214), the most common voting rules can be classified into positional voting systems or Condorcet consistent rules. The first group awards points to the alternatives according to their position in the voters' preference ranking. The winning alternative is the one that gets the most points. Condorcet consistent procedures determine the winning alternative by making a series of comparisons between alternatives. Thus, if a candidate is superior to the others in these comparisons, it is chosen. Voting procedures are summarised in Table 1.

According to Almeida et al. (2002), choosing the most appropriate voting procedure for the problem should be based on balancing behavioural issues and the social nature of the group of DMs, and the characteristics of the procedures. Despite the many advantages of voting procedures, acceptance of these tools in the supplier selection process remains low. They are nevertheless important alternatives for 
TABLE 1: Voting procedures.

\begin{tabular}{ll}
\hline Procedure & Description \\
\hline Borda & $\begin{array}{l}\text { Sorts alternatives, awarding points according to the DM's } \\
\text { preference. The winner is the one alternative with the most } \\
\text { points. }\end{array}$ \\
Involves comparing two alternatives. The winner is the \\
alternative that obtains an advantage over the other for a \\
larger number of DMs. If there is no difference, there is \\
indifference between alternatives.
\end{tabular}

Source: Almeida et al. 2002; Morais \& Almeida 2010

DMs to consider. In the next section the selection process currently used in the company is presented and discussed.

In 'The supplier selection process in the company' section, the supplier selection process in the company under study is presented in order to discuss the procedure and criteria considered by the company.

\section{The supplier selection process in the company}

The company under study is a publicly traded company, whose major shareholder is the Brazilian government. It acts as an energy company in the areas of exploration and production; refining, marketing and transportation of oil and gas, petrochemicals; and the distribution of oil products, electricity, biofuels and other renewable energy sources. Because it is a company in which the government is heavily involved, the process of supplier selection is regulated by a series of standards that establish the rules of the company's simplified bidding and contractual procedures.

The supplier selection process varies according to the type of product or service in question, and may be: (1) corporative: for items of corporate interest, that is large, more complex or greater value items; or (2) simplified, for other items. For both types of products, the supplier must be initially registered in the company's database via the company website. Then, an automatic classification of suppliers occurs depending on their expertise area and product or service provided.

The selection process accounts for various sets of criteria, such as: technical; economic; legal; health, safety and environment (HSE); management; credentialing and local content. These criteria are evaluated according to the type of supplier assessed, wherever applicable. A detailed explanation of the process for selecting a service provider follows, as it is the object of the application of the proposed
TABLE 2: Characterisation of the groups of criteria for service provider selection

\begin{tabular}{|c|c|c|}
\hline Area & Description & Criteria \\
\hline Technical & $\begin{array}{l}\text { Analyses the technical } \\
\text { capacity of the company } \\
\text { for the provision of } \\
\text { services by assessing the } \\
\text { resources required for } \\
\text { good performance }\end{array}$ & $\begin{array}{l}\text { Facilities (cr1), equipment (cr2), } \\
\text { materials (cr3), staff (cr4), technology } \\
\text { (cr5), company size (cr6), tradition in } \\
\text { service provision (cr7) and legal and } \\
\text { technical qualification }\end{array}$ \\
\hline Economic & $\begin{array}{l}\text { Searches for evidence of } \\
\text { the supplier's economic } \\
\text { solidity }\end{array}$ & $\begin{array}{l}\text { Credibility of accounts - evaluation of } \\
\text { the balance sheet and financial } \\
\text { statements }\end{array}$ \\
\hline Legal & $\begin{array}{l}\text { Monitors the regularity } \\
\text { of companies in meeting } \\
\text { their legal obligations }\end{array}$ & $\begin{array}{l}\text { Legal capacity, legal qualification, legal } \\
\text { and tax regularity, checking account, } \\
\text { terms and statements, risk, legal } \\
\text { management }\end{array}$ \\
\hline HSE & $\begin{array}{l}\text { Assesses the } \\
\text { implementation of the } \\
\text { management system } \\
\text { in HSE }\end{array}$ & $\begin{array}{l}\text { ISO } 14001 \text { (cr8), environmental } \\
\text { policy (cr9), planning EMS (cr10), } \\
\text { implementation and operation of the } \\
\text { EMS (cr11), checking and corrective } \\
\text { action of the EMS (cr12), critical } \\
\text { analysis for the administration of the } \\
\text { EMS (cr13), OHSAS18001 (cr14), } \\
\text { politics OHS (cr15), OHSAS planning } \\
\text { (cr16), implementation and operation } \\
\text { of OHSMS (cr17), checking and } \\
\text { corrective action of OHSAS (cr18), } \\
\text { critical analysis for the administration } \\
\text { of the OHSAS (cr19), HSE additional } \\
\text { information, offshore HSE additional } \\
\text { requirements }\end{array}$ \\
\hline Management & $\begin{array}{l}\text { Managerial behaviour of } \\
\text { the companies, evaluating } \\
\text { the commitment to } \\
\text { quality and continuous } \\
\text { improvement }\end{array}$ & $\begin{array}{l}\text { ISO9001 (cr20), quality management } \\
\text { system (cr21), management } \\
\text { responsibility (cr22), resource } \\
\text { management (cr23), accomplishment } \\
\text { of the product (cr24), measurement, } \\
\text { analysis and improvement (cr25), NQA } \\
\text { (national quality award) excellence } \\
\text { policy (cr26), offshore additional } \\
\text { management requirements }\end{array}$ \\
\hline Local content & $\begin{array}{l}\text { Evaluates the percentage } \\
\text { of the local content } \\
\text { according to the Brazilian } \\
\text { National Petroleum } \\
\text { Agency }\end{array}$ & Local content \\
\hline
\end{tabular}

EMS, environmental management system; HSE, health, safety and environment; OHS, occupational health and safety; OHSMS, occupational health and safety assessment series.

model. The groups and their criteria for selecting this type of supplier are shown in Table 2.

After obtaining the information about the potential suppliers, the evaluation step occurs. This step evaluates the information provided by the potential supplier and is carried out by specialised teams in the areas corresponding to the criteria. Based on evidence verified, scores are assigned to each supply item. As a final result, the supplier is classified and may be available to receive purchase orders made by business units. During the process, many experts conduct assessments in their areas of expertise. Thus, this process is characterised as a group decision-making problem.

Next, we propose a model for selecting suppliers, which is considered to be a group decision-making problem.

\section{Proposed group decision model for selecting suppliers for a Brazilian oil company}

The model in Figure 1 is proposed in order to support decision-making on supplier selection in a group decisionmaking context.

Firstly, suppliers register themselves on the company's website. At that time, they provide some general data along 


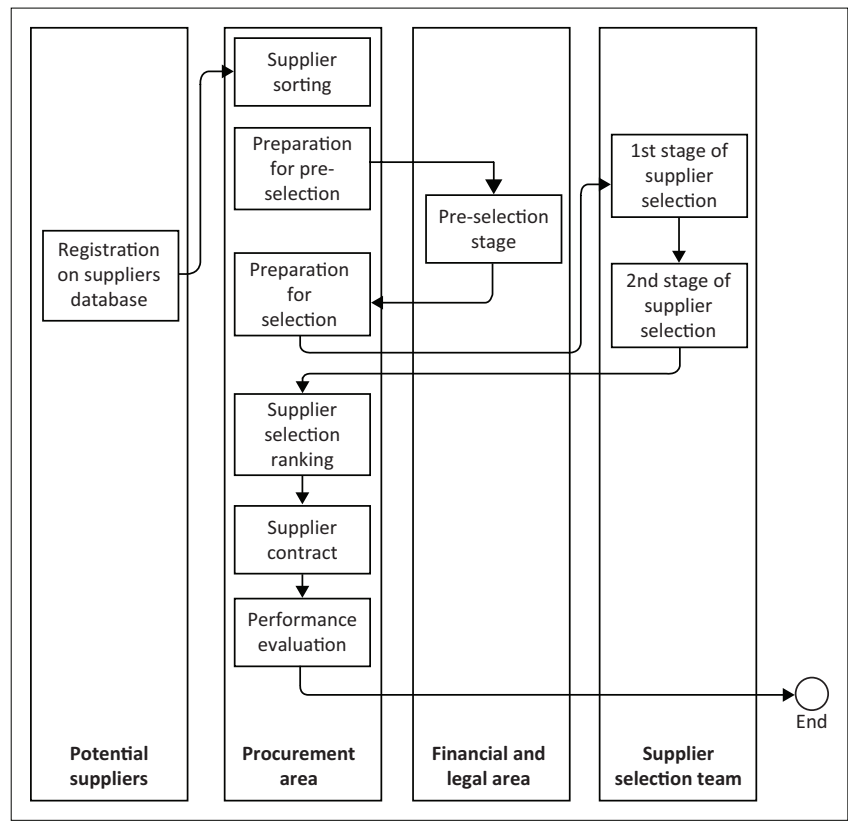

FIGURE 1: Group decision-making supplier selection model.

with the products or services that they provide. This information is then available for review by the contracting company. After this stage, they are classified and clustered according to the type of delivery that they offer. Based on information made available by the suppliers, the contracting company sorts the suppliers by allocating each one to its respective class according to the products or services it provides and the type of company operation. A database of suppliers is built for each item that the company might need. This database can be consulted by the company at any time, depending on its supply needs.

When the contracting company needs a product or service, a search for registered suppliers is made on the company's database to identify the candidates available in that period. The steps proposed up to this point are already performed by the company in its current selection process.

The step of supplier pre-selection is then proposed. This must be evaluated on aspects of 'economic', 'legal' and 'local content', represented by the criteria shown in Table 1 . They are basic prerequisites for accepting a supplier. The aspects considered in these three groups of criteria are regulated by law and may result in a candidate being excluded at this stage. If a candidate does not meet these prerequisites, it is automatically removed from the process. If the prerequisites are met, the candidate proceeds to the next stage of selection.

Next is the first phase for selecting suppliers. At this point, the relevant criteria are considered, which are related to the groups shown in Table 1. Each specialist, depending on his or her area of expertise, performs an analysis separately using scales, criteria, methods and other specific parameters. This approach is beneficial because it facilitates how the experts performed their analysis, as they may do so independently, without the need for consensus with other specialists. However, these experts are from different areas of the organisation and conflicting objectives and interests between the different sectors of the organisation commonly arise.

To provide decision support, one outranking method was chosen mainly because of its non-compensatory nature, that is, a positive performance in a given criterion does not compensate for poor performance on other criteria. Thus, all the information available for evaluating the alternatives is considered. Among the outranking methods, the PROMETHEE family was selected owing to its ability to consider the DM's hesitation in evaluating alternatives, and therefore, thresholds of indifference and preference are considered. The PROMETHEE II method was selected to implement the model because it generates a ranking of the alternatives by considering both the ascending and descending rankings. In addition, one of the requirements for applying the voting procedure by quartiles is to use each DM's alternative rankings, so that the final ranking can be obtained. Furthermore, DMs find it easy to understand the method and this enables the use of indifference and preference thresholds.

According to Brans et al. (1998) and Brans and Mareschal (2005), the PROMETHEE family of methods stands out by involving physical and economic concepts and parameters that DMs find are easy to understand and interpret. An evaluation matrix consists of alternatives that should be evaluated under multiple criteria, where $a$ and $b$ are alternatives to this set of alternatives, and $g_{j}(a)$ and $g_{j}(b)$ are the gains that the alternatives represent for criterion $j$. Brans and Vincke (1985:647-654) identify assigned weights $p_{j^{\prime}}$ which represent the degree of importance for each criterion, and the outranking degree $\pi(a, b)$ is computed according to Equation 1:

$\pi(a, b)=\frac{1}{P} \sum_{j=1}^{n} p_{j} F_{j}(a, b)$, where $P=\sum_{j=1}^{n} p_{j}$,

[Eqn 1]

where $F_{j}(a, b)$ is a number between 0 and 1 that increases when $g_{j}(a)>g_{j}(b)$ increases and is equal to zero if $g_{j}(a) \leq g_{j}(b)$. To find the value of $F_{j}(a, b)$, the DM can choose, for each criterion, one of the six forms of curves, in accordance with its indifference $(q)$ and preference $(p)$ thresholds.

Table 3 shows the functions that can be used, according to a DM's preference structure, for each criterion, as adapted from Brans, Vincke and Mareschal (1986:228-232).

After obtaining the values of $\pi(a, b)$, two complete preorders can be obtained viz. Equation 2 representing a sort of the actions following a descending order of the flow indexes $\varphi^{+}(a)$, and Equation 3 following an ascending order of the indexes $\varphi^{-}(a)$ :

$$
\begin{array}{ll}
\varphi^{+}(a)=\frac{1}{n-1} \sum_{b \in A} \pi(a, b) & \text { (Descending flow) } \\
\varphi^{-}(a)=\frac{1}{n-1} \sum_{b \in A} \pi(b, a) & \text { (Ascending flow) }
\end{array}
$$


TABLE 3: Preference functions.

\begin{tabular}{lcc}
\hline PABLefence function & Comparison factors & Value obtained \\
\hline Usual & $g_{j}(a)-g(b)>0$ & $P_{j}(a, b)=1$ \\
& $g_{j}(a)-g(b) \leq 0$ & $P_{j}(a, b)=0$ \\
U-shape & $g_{j}(a)-g(b)>q$ & $P_{j}(a, b)=1$ \\
& $g_{j}(a)-g(b) \leq q$ & $P_{j}(a, b)=0$ \\
V-shape & $g_{j}(a)-g(b)>p$ & $P_{j}(a, b)=1$ \\
& $g_{j}(a)-g(b) \leq p$ & $P_{j}(a, b)=\left[g_{j}(a)-g_{j}(b)\right] / p$ \\
& $g_{j}(a)-g(b) \leq 0$ & $P_{j}(a, b)=0$ \\
Level & $\left|g_{j}(a)-g(b)\right|>p$ & $P_{j}(a, b)=1$ \\
& $q<\left|g_{j}(a)-g(b)\right| \leq p$ & $P_{j}(a, b)=0,5$ \\
Linear & $\left|g_{j}(a)-g(b)\right| \leq q$ & $P_{j}(a, b)=0$ \\
& $\left|g_{j}(a)-g(b)\right|>p$ & $P_{j}(a, b)=1$ \\
& $q<\left|g_{j}(a)-g(b)\right| \leq p$ & $P_{j}(a, b)=\left[\left|g_{j}(a)-g_{j}(b)\right|-q\right] /$ \\
Gaussian & $\left|g_{j}(a)-g(b)\right| \leq q$ & $(p-q)$ \\
& $\left|g_{j}(a)-g(b)\right|>0$ & $P_{j}(a, b)=0$ \\
& $\left|g_{j}(a)-g(b)\right| \leq 0$ & whe preference increases \\
\hline
\end{tabular}

Source: Brans et al. (1986)

The intersection of these two flows generates a partial pre-order. That ranking is the result of applying the PROMETHEE I method. The PROMETHEE II method orders the actions following the liquid flow $(\varphi(a))$ in Equation 4:

$\varphi(a)=\varphi^{+}(a)-\varphi^{-}(a)$

[Eqn 4]

Thus, a single complete pre-order of alternatives is obtained.

In the second supplier selection stage, the DMs' views are aggregated to obtain a group decision. The analysis performed by the specialists who represent the various areas of the company are processed into a single analysis that represents the company's position. For this study, the voting procedure by quartiles was selected because it is easy to understand, because use was made of ranked results from the PROMETHEE II application and because it is a method designed for the problematic of choice, which is useful for the supplier selection process.

The voting procedure by quartiles, proposed by Morais and Almeida (2010; 2012), analyses the best and worst alternatives as classified by all DMs. It then applies two types of counts based on the principles of the edge-counting procedure. To do so, the method analyses the information taken from the alternative rankings of each DM. Rankings can be obtained by applying a multi-criteria decision aid method that generates an ordering of alternatives based on the DM's preference. The method is applied according to three stages of exploration (filter, veto and choose) as shown in Figure 2.

As shown in Morais and Almeida (2012:44-45), where $k=$ $\left\{D M_{1}, D M_{2}, \ldots, D M_{k}\right\}$ is the set of DMs, each DM provides a ranking of alternatives, represented by $i=\{A, B, C, \ldots\}$. Following the rankings, the filter phase occurs and the alternatives that are in the upper and lower quartile are analysed. Therefore, it is necessary to define which alternatives are in these quartiles. Firstly, regarding the upper quartile, it is necessary to establish which alternatives are among the $25 \%$ best ranked for each DM. In order to identify

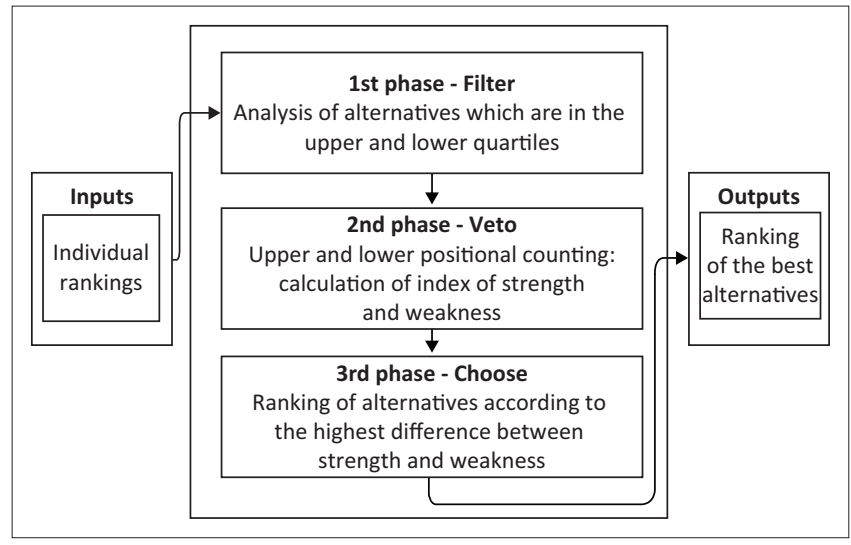

Source: Morais and Almeida 2010, 2012

FIGURE 2: Method overview.

the composition of the upper quartile, the notation presented in Equation 5, where $n$ is the total number of alternatives evaluated, is applied.

$x=\frac{n}{4} \quad($ rounded up $)$

[Eqn 5]

Then, for the items allocated in the upper quartile, the number of DMs who allocate the alternatives in that quartile is evaluated. Considering $U_{i}$ as the number of times that alternative $i$ appears in the upper quartile, its value is calculated as shown in Equation 6.

$U_{i}=\sum_{k=1}^{m} u_{i}^{k}, \quad \forall i, k \quad \forall j=1, \ldots, x$

[Eqn 6]

where $u_{i}^{k}$ assumes values 0 or 1 , according to the presence of the alternative in the upper quartile of $D M_{k}$. The alternatives that did not receive votes from any of the DMs $\left(U_{i}=0\right)$ are eliminated. After the first filtration, the alternatives that were allocated in the lower quartile are analysed. Their composition can be defined by Equation 7 .

$y=\left(\frac{3 n}{4}\right)+1 \quad($ truncated $)$

[Eqn 7]

Analogously to the analysis performed for the upper quartile, the number of DMs who are against the alternatives is counted. For that purpose, the number of times the alternative $i$ appears in the lower quartile is calculated according to Equation 8.

$L_{i}=\sum_{k=1}^{m} l_{i}^{k}, \quad \forall i, k \quad \forall j=1, \ldots, x$

[Eqn 8]

where $l_{i}^{k}$ assumes values 0 or 1 , according to the presence of the alternative $i$ in the upper quartile for $D M_{k}$. At the end of the filtering stage, alternatives with more votes against than in favour $\left(L_{i} \geq U_{\mathrm{i}}\right)$ are eliminated from the set of alternatives. The remaining alternatives then proceed to the veto stage.

In the veto stage, a positional count is performed based on the 'edge' method. This procedure assigns to each ranking 
a value which varies according to the ranking's position. The proposed method, however, only analyses the alternatives that are in the upper and lower quartiles. To evaluate the upper quartile, the score is computed as follows: 1 for the last position (upper quartile limit: $x$ ), 2 for the penultimate position, $\ldots, x$ for the first position. The score for each alternative is totalled and each receives a score called 'strength of the alternative', as expressed in Equation 9.

$F_{i}=\sum_{k=1}^{m} \sum_{j=1}^{x}(x-j+1) q_{i j}^{k} \quad \forall i, k \quad \forall j=1, \ldots, x$

[Eqn 9]

where $q_{i j}^{k}$ assumes the value 1 when alternative $i$ is in position $j$ for the DM $k$; or 0 otherwise. As $i$ corresponds to the alternatives in the upper quartile, $j$ is the position in the upper quartile, ranging from 1 to $x$, and $k$ represents a DM. Given that, the value of the strength of the alternative $A$ is given as seen in Equation 10:

$$
\begin{aligned}
F_{A}= & (x)\left(q_{A 1^{s t}}^{1}+q_{A 1^{s t}}^{2}+\ldots+q_{A 1^{s t}}^{m}\right)+\ldots \\
& +(2)\left(q_{A(x-1)^{t h}}^{1}+q_{A(x-1)^{t h}}^{2}+\ldots+q_{A(x-1)^{t h}}^{m}\right) \\
& +(1)\left(q_{A x^{t h}}^{1}+q_{A x^{t h}}^{2}+\ldots+q_{A x^{t h}}^{m}\right)
\end{aligned}
$$

For the analysis of the lower quartile, the points are inversely assigned to each position, namely, $x$ for the last one placed in the ranking, $(x-1)$ for the penultimate position, ..., and 1 for the one placed first among the alternatives of the lower quartile. The points assigned to each alternative are summed and the alternative receives a score called the 'weakness of the alternative' $\left(f_{i}\right)$, as per Equation 11.

$$
f_{i}=\sum_{k=1}^{m} \sum_{j=y}^{n}(j-y+1) q_{i j}^{k} \quad \forall i, k \quad \forall j=y, \ldots, n
$$

where $q_{i j}^{k}$ assumes the value 1 if alternative $i$ is in position $j$ for $D M_{k^{\prime}}$ or 0 otherwise; $i$ refers to the remaining alternatives in the lower quartile; $j$ is the position ranging from the first position in the lower quartile $\left(y^{\text {th }}\right)$ to the last one in the ranking $\left(n^{\text {th }}\right)$, for each $D M_{k}$. The weakness of the alternative $\mathrm{A}$ is given by Equation 12 .

$$
\begin{aligned}
f_{A}= & (1)\left(q_{A y^{t h}}^{1}+q_{A y^{t h}}^{2}+\ldots+q_{A y^{t h}}^{m}\right)+\ldots \\
& +(2)\left(q_{A(y+1)^{t h}}^{1}+q_{A(y+1)^{t h}}^{2}+\ldots+q_{A(y+1)^{t h}}^{m}\right) \\
& +(x)\left(q_{A n^{t h}}^{1}+q_{A n^{t h}}^{2}+\ldots+q_{A n^{t h}}^{m}\right)
\end{aligned}
$$

Once the values of $F_{A}$ and $f_{A}$ are obtained, the intensity of discordance must be evaluated to see if the alternative should be discarded. Thus, if $f_{i} \geq F_{i^{\prime}}$ there is high opposition to the alternative being considered among the best for the group of DMs. Therefore, the alternative $i$ is eliminated. It is also possible to establish more restrictive veto thresholds by adding a multiplier factor to the evaluation condition of the alternatives as shown in Equation 13.

$f_{i} \geq \beta F_{i}$

where $\beta$ represents the percentage of the value of $f_{i^{\prime}}$, relative to $F_{i}$, that the DMs are willing to accept. Decision-makers can obtain the $\beta$ value by discussing with each other what this should be. The next step involves the process of choice. From the values of $f_{i}$ and $F_{i}$, the intensities of preference for each alternative are calculated as per Equation 14.

$\alpha_{i}=F_{i}-f_{i}$

[Eqn 14]

Thus, the alternative with the greatest $\alpha_{i}$ value is chosen. In case of a tie, an analysis of the alternatives should be conducted in order to verify which one most DMs prefer.

Finally, the supplier is contracted and as relations with the supplier then start occurring, its performance is constantly evaluated. Multi-criteria decision support methods and group decision-making can be used during the assessment process.

The following sub-section describes an application of the model to selecting service providers for the oil and gas company.

\section{A numerical example}

To illustrate the application of the model, hypothetical data were used for selecting contract builders of floating platforms called FPSO (floating production unit, storage and oil transfer) which are used to extract oil and gas at sea, from pre-salt fields. It is public knowledge that the company is involved in a public inquiry into problems related to one of its floating platform contractors. Ten potential suppliers are evaluated (S1 to S10) from both Brazilian and foreign companies.

In this context, the points of view of four DMs (DM1, DM2, DM3 and DM4) will be considered in the analysis in Table 4.

For this analysis, the criteria used are described in Table 5. Some criteria in Table 2 were not considered. However, these criteria can be entered in other applications depending on the DM's needs.

The criteria belonging to the 'economic', 'legal' and 'local content' groups should be evaluated in the pre-selection

TABLE 4: Description of the role of the decision-maker.

\begin{tabular}{ll}
\hline DM & Area \\
\hline DM1 & $\begin{array}{l}\text { Represents the area of gas and energy, focusing on natural gas and } \\
\text { other energy }\end{array}$ \\
DM2 & $\begin{array}{l}\text { Represents the corporate and service sector, which includes HSE sectors } \\
\text { and social responsibility }\end{array}$ \\
DM3 & $\begin{array}{l}\text { Represents the area of engineering and materials technology } \\
\text { DM4 }\end{array}$ \\
\hline
\end{tabular}

DM, decision-maker; HSE, health, safety and environment. 
TABLE 5: Criteria used in the application.

\begin{tabular}{|c|c|c|}
\hline $\mathrm{Cr}$ & Criterion & Description \\
\hline 1 & Facilities & Evaluates the quantity and quality of administrative and industrial facilities for conducting the service \\
\hline 2 & Equipment & $\begin{array}{l}\text { Evaluates the quantity, characteristics, condition and adequacy of the company's equipment and the lease and mobilisation capacity of } \\
\text { appropriate equipment }\end{array}$ \\
\hline 3 & Materials & Analyses the supply capacity of materials linked to the type of service provided \\
\hline 4 & Staff & $\begin{array}{l}\text { Evaluates the qualifications and experience of the company's technical and managerial staff and the staffing capacity with qualifications } \\
\text { and experience }\end{array}$ \\
\hline 5 & Technology & $\begin{array}{l}\text { Assesses how the company is able to perform services, its capacity for developing and monitoring detailed schedules of activities related to } \\
\text { implementing services and the management capacity of service providers }\end{array}$ \\
\hline 6 & Company size & $\begin{array}{l}\text { Evaluates the potential physical load, based on recently performed services, and the current capacity, based on the limitations of facilities, } \\
\text { technology, equipment and personnel }\end{array}$ \\
\hline 7 & Tradition in services & Proves the company's experience over previous years of having carried out identical or similar characteristics of the service now required \\
\hline 8 & ISO 14001 & Checks the environmental management system certification \\
\hline 9 & Environmental policy & Analyses the composition of the company's environmental policy, as defined, documented, implemented, maintained and disseminated \\
\hline 10 & EMS planning & $\begin{array}{l}\text { Evaluates how the organisation establishes and maintains procedures to identify the environmental aspects of its activities and whether the } \\
\text { organisation establishes and maintains programmes to achieve its goals }\end{array}$ \\
\hline 11 & $\begin{array}{l}\text { EMS implementation and } \\
\text { operation }\end{array}$ & $\begin{array}{l}\text { Involves analysing aspects of structure and responsibility; training, awareness and competence; communication; documentation; operational } \\
\text { control; and preparedness and response to emergencies, under the environmental management system }\end{array}$ \\
\hline 12 & $\begin{array}{l}\text { Checking and corrective } \\
\text { action of the EMS }\end{array}$ & $\begin{array}{l}\text { Involves analysing issues related to monitoring and measurement; treatment of non-conformities and corrective actions; records; } \\
\text { and audits of EMS }\end{array}$ \\
\hline 13 & Critical analysis of EMS & Assesses how top management participates in the analysis and improvement of the environmental management system \\
\hline 14 & OHSAS18001 & Checks for management certification for the environmental management area \\
\hline 15 & OHS policy & Reviews the adequacy and implementation of the $\mathrm{OH} \& \mathrm{~S}$ policy \\
\hline 16 & OHSAS planning & $\begin{array}{l}\text { Evaluates aspects of planning for hazard identification, risk assessment and control; legal requirements; goals; and the OHS management } \\
\text { programme }\end{array}$ \\
\hline 17 & $\begin{array}{l}\text { OHSAS implementation and } \\
\text { operation }\end{array}$ & $\begin{array}{l}\text { Involves analysing issues related to documents and data control; preparation and emergency response; operational control; documentation; } \\
\text { consultation and communication; training, awareness and competence; structure and OHSAS responsibility }\end{array}$ \\
\hline 18 & $\begin{array}{l}\text { Checking and corrective } \\
\text { action of OHSAS }\end{array}$ & $\begin{array}{l}\text { Evaluates the registry and registry management; audits; accidents, incidents, non-conformity and corrective and preventive actions; and } \\
\text { monitoring and measurement of OHSAS performance }\end{array}$ \\
\hline 19 & Critical analysis of OHSAS & Checks senior management's participation in analysing and improving the $\mathrm{OH} \& \mathrm{~S}$ management system \\
\hline 20 & ISO9001 & Checks that the company has an ISO 9001 certificate \\
\hline 21 & Quality management system & Analyses how the organisation implements the quality manual and control records and documents \\
\hline 22 & Management responsibility & $\begin{array}{l}\text { Assesses the commitment of senior management; customer focus; quality policy; planning; responsibility, authority and communication; and } \\
\text { critical analysis by top management }\end{array}$ \\
\hline 25 & $\begin{array}{l}\text { Measurement, analysis and } \\
\text { improvement }\end{array}$ & Measurement and monitoring; Procurement \\
\hline 26 & Policy of excellence (NQA) & Evaluates measurement and monitoring; product control non-conformity; data analysis; and improvements \\
\hline
\end{tabular}

EMS, environmental management system; OHS, occupational health and safety; OHSAS, occupational health and safety assessment series; NQA, national quality award.

stage proposed in the model. Similarly, the 'legal and technical license' criterion should also be considered in this preliminary phase. The 'additional information SMS', 'additional requirements SMS offshore' and 'additional management requirements offshore' criteria may be included in the model, when relevant. The analyses that DMs perform are independent.

Each DM can divide the criteria into sub-criteria, use different weights, ignore certain criteria or use different multi-criteria methods as needed. This procedure is possible because the individual analyses are independent of each other, as only the rankings obtained from the first phase are used as inputs to the voting procedure by quartiles.

Decision-makers can determine the scales best suited to their preference structure. For most of the criteria in this application, a qualitative scale of five points, convertible into a numerical scale, was used to evaluate the performance of the candidates. For criteria Cr8, Cr13 and Cr19, a two-point scale (yes or no) was used, as shown in Table 6.

The evaluation scale labels may vary depending on the criteria evaluated, but they always respect the interpretation
TABLE 6: Evaluation scale.

\begin{tabular}{lcccccc}
\hline Very low & Low (R) & Average (M) & High (H) & Very high (MB) & Yes & No \\
\hline 1 & 2 & 3 & 4 & 5 & 1 & 0 \\
\hline
\end{tabular}

of the five points scale. Depending on the situation, scales used for criteria may differ in accordance with the DM's needs.

Table 7 shows the normalised weights assigned by each of the DMs to each criterion, for the application of PROMETHEE II.

If a DM considers that a criterion is not important for the evaluation, it is assigned a zero weight. Because ratings by DMs are independent, each DM can consider the criteria in accordance with his or her point of interest.

After weights were assigned, each alternative was evaluated against each criterion by each of the DMs, independently. The usual criteria were adopted for all criteria and all DMs. Any difference in the evaluation of alternatives denotes outranking the alternative with the higher performance compared to that with the lower performance. Meanwhile, the manager can follow other 


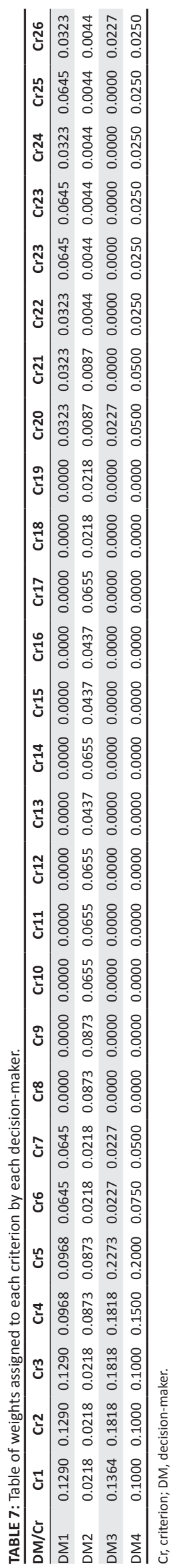

functions to represent his or her preferences, which gives the proposed model important flexibility.

By applying the PROMETHEE II method, the rankings were obtained for the selection of the 10 suppliers, as shown in Table 8.

A sensitivity analysis was conducted to assess the robustness of the results when small variations in the values of the parameters are considered. For the sensitivity analysis, the authors adjusted the weights assigned to each criterion. The analysis accounted for an increase of $15 \%$ in the weight of each criterion, and a proportionate reduction in the others. There were only small changes in the ranking of the alternatives, suggesting that the results obtained are very stable.

After obtaining the individual points of view, the quartile voting procedure was applied to identify the best ranked alternative for the group of DMs among the 10 candidates. By applying Equations 5 and 7, the upper and lower quartiles are defined and reported in Table 9.

The results expressed in Table 10 come from applying the first phase of the filter to the upper quartile, where the alternatives S3, S6 and S10 are eliminated because they have not received any votes.

In the second filtering phase, an analysis is performed on the lower quartile, as shown in Table 11.

At this stage, the alternatives S4 and S9 are eliminated based on the criterion considered from the voting by quartiles procedure. All the alternatives go to the veto stage, as per Tables 12 and 13.

TABLE 8: Ranking of service providers by four decision-makers.

\begin{tabular}{lllll}
\hline Ranking & DM 1 & DM 2 & DM 3 & DM 4 \\
\hline 1st & S8 & S8 & S8 & S1 \\
2nd & S1 & S2 & S1 & S8 \\
3rd & S4 & S7 & S5 & S9 \\
4th & S7 & S1 & S9 & S4 \\
5th & S5 & S9 & S2 & S2 \\
6th & S2 & S6 & S4 & S5 \\
7th & S3 & S5 & S7 & S7 \\
8th & S9 & S4 & S6 & S6 \\
9th & S6 & S3 & S3 & S3 \\
10th & S10 & S10 & S10 & S10
\end{tabular}

DM, decision-maker.

TABLE 9: Applying the voting procedure to supplier selection.

\begin{tabular}{lccccl}
\hline Ranking & DM 1 & DM 2 & DM 3 & DM 4 & Quartile \\
\hline 1st & S8 & S8 & S8 & S1 & Upper quartile \\
2nd & S1 & S2 & S1 & S8 & Upper quartile \\
3rd & S4 & S7 & S5 & S9 & Upper quartile \\
4th & S7 & S1 & S9 & S4 & - \\
5th & S5 & S9 & S2 & S2 & - \\
6th & S2 & S6 & S4 & S5 & - \\
7th & S3 & S5 & S7 & S7 & - \\
8th & S9 & S4 & S6 & S6 & Lower quartile \\
9th & S6 & S3 & S3 & S3 & Lower quartile \\
10th & S10 & S10 & S10 & S10 & Lower quartile \\
\hline
\end{tabular}

$\mathrm{DM}$, decision-maker. 
TABLE 10: Filtering step for upper quartile.

\begin{tabular}{lll}
\hline & Filter $\mathbf{1}$ & \\
\hline Alternatives & $\boldsymbol{U}_{\boldsymbol{i}}$ & Action \\
\hline S1 & 3 & Proceed \\
S2 & 1 & Proceed \\
S3 & 0 & Eliminate $\left(U_{3}=0\right)$ \\
S4 & 1 & Proceed \\
S5 & 1 & Proceed \\
S6 & 0 & Eliminate $\left(U_{6}=0\right)$ \\
S7 & 1 & Proceed \\
S8 & 4 & Proceed \\
S9 & 1 & Proceed \\
S10 & 0 & Eliminate $\left(U_{10}=0\right)$ \\
\hline
\end{tabular}

$U_{i}$, number of times that supplier $i$ appears in the upper quartile; $U_{3}$ number of times that supplier 3 appears in the upper quartile; $U_{\epsilon}$ number of times that supplier 6 appears in the upper quartile; $U_{10}$ number of times that supplier 10 appears in the upper quartile; $\mathrm{S}$, supplier.

TABLE 11: Filtering step for lower quartile.

\begin{tabular}{lll}
\hline & Filter $\mathbf{2}$ & \\
\hline Alternatives & $\boldsymbol{L}_{\boldsymbol{i}}$ & Action \\
\hline S1 & 0 & Proceed \\
S2 & 0 & Proceed \\
S4 & 1 & Eliminate $\left(L_{4} \geq U_{4}\right)$ \\
S5 & 0 & Proceed \\
S7 & 0 & Proceed \\
S8 & 0 & Proceed \\
S9 & 1 & Eliminate $\left(L_{9} \geq U_{9}\right)$ \\
\hline
\end{tabular}

$L_{i}$ number of times that supplier $\mathrm{i}$ appears in the lower quartile; $L_{4}$ number of times that supplier 4 appears in the lower quartile; $U_{4}$, number of times that supplier 4 appears in the upper quartile; $L_{g}$ number of times that supplier 9 appears in the lower quartile; $U_{g}$ number of times that supplier 9 appears in the upper quartile.

TABLE 12: Veto stage to the upper quartile.

\begin{tabular}{lcccc}
\hline Alternatives & \multicolumn{3}{c}{ Veto $\mathbf{1}$} & $\begin{array}{c}\text { Strength of } \\
\text { alternatives }\end{array}$ \\
\cline { 2 - 4 } & $\boldsymbol{j}=\mathbf{1}^{\text {st }}$ & $\boldsymbol{j}^{\mathbf{2} \mathbf{2}^{\text {nd }}}$ & $\boldsymbol{j}_{\mathbf{=} \mathbf{3}^{\text {rd }}}$ & \\
\hline$x-j+1$ & 3 & 2 & 1 & $F_{i}$ \\
S1 & 1 & 2 & 0 & 7 \\
S2 & 0 & 1 & 0 & 2 \\
S5 & 0 & 0 & 1 & 1 \\
S7 & 0 & 0 & 1 & 1 \\
S8 & 3 & 1 & 0 & 11 \\
\hline
\end{tabular}

TABLE 13: Veto stage to the lower quartile.

\begin{tabular}{lcccc}
\hline Alternatives & \multicolumn{3}{c}{ Veto $\mathbf{2}$} & $\begin{array}{c}\text { Weakness of } \\
\text { alternatives }\end{array}$ \\
\cline { 2 - 4 } & $\boldsymbol{j}=\mathbf{8}^{\text {th }}$ & $\boldsymbol{j = \mathbf { 9 } ^ { \text { th } }}$ & $\boldsymbol{j = 1 \mathbf { 1 } ^ { \text { th } }}$ & \\
\hline$j-y+1$ & 1 & 2 & 3 & $f_{i}$ \\
S1 & 0 & 0 & 0 & 0 \\
S2 & 0 & 0 & 0 & 0 \\
S5 & 0 & 0 & 0 & 0 \\
S7 & 0 & 0 & 0 & 0 \\
S8 & 0 & 0 & 0 & 0 \\
\hline
\end{tabular}

It is observed that for any alternative, the exclusion condition $\left(f_{i} \geq F_{i}\right)$ is accepted. Thus, the five alternatives go to the selection step, where $\alpha$ is the corresponding value as shown in Table 14.

Based on the highest score from the analysis, supplier S8 is the most suitable for the company under study, followed by alternatives S1, S2, S5 and S7 respectively. S5 and S7 suppliers are tied for fourth place in the ranking. The model is feasible for more complex cases than the one depicted in this study. By way of comparison, based on the results
TABLE 14: Choice stage for the remaining alternatives.

\begin{tabular}{lcc}
\hline Alternative & $\alpha_{i}$ & Rank \\
\hline S8 & 11 & 1 st \\
S1 & 7 & 2nd \\
S2 & 2 & 3rd \\
S5 & 1 & 4 th \\
S7 & 1 & 4th \\
\hline
\end{tabular}

$\mathrm{S}$, supplier; $a_{i}$, score of alternative $i$.

TABLE 15: Comparison of the results obtained by applying the Copeland, Borda, Approval voting and Condorcet procedures.

\begin{tabular}{lccccc}
\hline Ranking & Quartiles voting & Copeland & Borda & Approval voting & Condorcet \\
\hline 1st & S8 & S8 & S8 & S8 & S8 \\
2nd & S1 & S1 & S1 & S1 & - \\
3rd & S2 & S2 & S2 & S2, S4, S5, S9 & - \\
4th & S5 & S9 & S9 & - & - \\
5th & - & S4, S5, S7 & S4, S5, S7 & - & - \\
6th & - & - & - & - & \\
7th & - & - & - & - & - \\
8th & - & S6 & S6 & - & - \\
9th & - & S3 & S3 & - & - \\
10th & - & S10 & S10 & - & - \\
\hline
\end{tabular}

S, supplier.

in Table 14, the Copeland, Borda, Approval voting and Condorcet procedures were applied to this case study. The 'Voting with agenda', and Hare procedures were not considered for this application because the rankings obtained are not sufficient to allow the application of these procedures; thus, the DMs would need more information. The results obtained by applying the aforementioned procedures are presented in Table 15.

Based on the analysis of the results obtained from applying the voting procedures, note that supplier S8 is evaluated as the best choice in all procedures and supplier S1 is the second best, according to the DMs' individual evaluations. Supplier $\mathrm{S} 2$ is placed in third position by all methods. However, in the approval voting procedure, S2 is evaluated at the same level as S4, S5 and S9. The results obtained from the numerical example are discussed in the following section, with emphasis on the managerial implications of the results. Thus, choosing the most suitable voting procedure is crucial to adequately representing the views of the decision-making group.

\section{Results and discussion}

Applying the model, enabled a useful ranking to be built and used during supplier selection. Therefore, we examined the evaluations made by four DMs of different profiles, which suggests their evaluations had differing objectives. Thus, conflicts may arise among the DMs involved in the decision process. When the selection process is not properly structured, subjective factors, such as empathy and negotiation experience, can influence decision-making in the organisation which may in turn lead to undesired results. The proposed model considers the evaluation conducted by each of the agents involved and arrives, quite transparently, at the best solution by considering the views of all the DMs involved. Consequently, it minimises DMs' remorse, thereby increasing the acceptance of the results obtained from the decision-making process. 
As for the results obtained by the numerical application, the results in Table 9 are compared to those presented in Table 14. The results are presented in Figure 3.

As shown in Figure 3, suppliers S8 and S1 performed much better than the others when the quartiles voting procedure was applied. Vendor S8 is rated as the best option by three out of the four DMs and is the winner supplier in the quartiles voting procedure. Supplier S1 is rated in second position because it also received good evaluations from the DMs and is even evaluated as the best by one of them. Therefore, a point of conflict can arise with this DM, as he regards S1 as the best and S8 as the second best alternative. However, because of the fact that this DM has placed S8 as the secondlargest supplier in his assessment, the conflict is expected to be dissipated quickly. In the other ranking positions, other possibilities for potential conflicts between the DMs are noticeable. It is worth mentioning, for example that suppliers S7 and S9 are ranked among the four best positions by two DMs. However, the result of the voting procedure assigns the third and fourth place to S2 and S5. This situation occurs because S7 and S9 appear in low positions in the rankings of the other two DMs, which consequently led these suppliers to be surpassed by S2 and S5, and which all four DMs regard as having a more consistent performance.

Regarding the voting procedures, there were no significant changes from the first positions in the ranking obtained. However, depending on the procedure selected, there were changes in the other ranking positions. Thus, DMs should choose the most appropriate procedure very carefully in order to understand the characteristics of each procedure.

In the following section, final considerations of the study are presented in addition to suggestions for future studies.

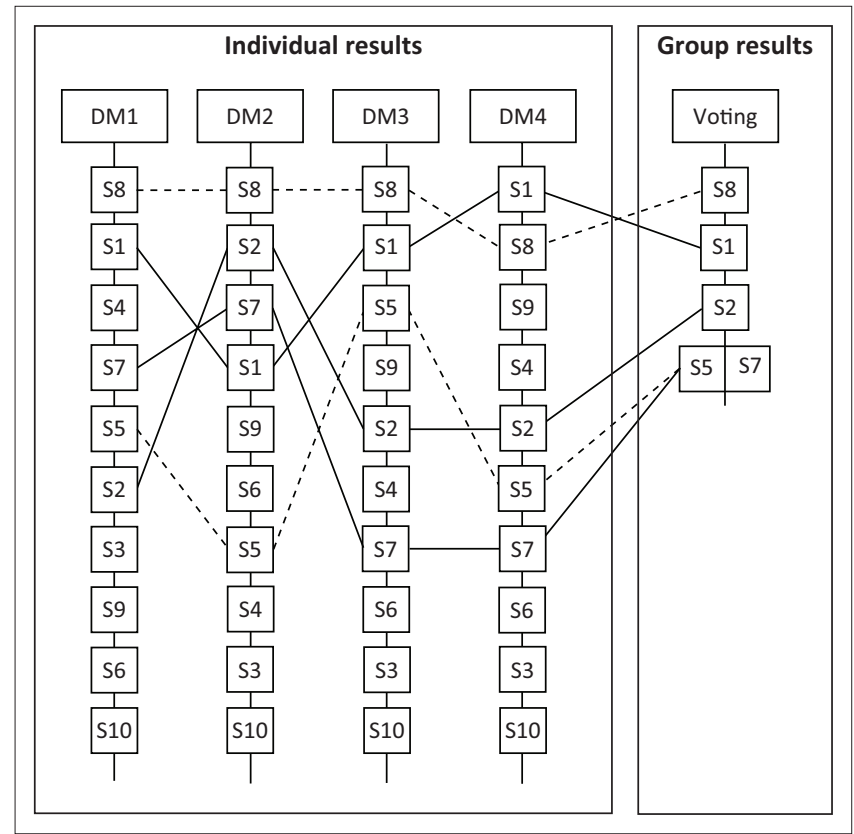

FIGURE 3: Comparison of individual and group results.

\section{Conclusions}

The activity of selecting suppliers has a significant impact on the success of an entire supply chain. In the oil and gas industry, it is no different. In the context of a company that undergoes heavy interference by the government and must follow procedures expressed in legislation, the process of selecting suppliers becomes even more complex.

To address this problem, a model for supplier selection based on multi-criteria decision support for a group of DMs was proposed. The proposed model consists of consecutive phases and aims to facilitate the decision-making process for selecting suppliers that meet the different demands of the various areas of the company. By using an aggregation approach to the DMs' choices, the model carries a high degree of flexibility by allowing every DM to make their own assessment, considering criteria, parameters, weights and different multi-criteria methods adapted to each individual. Based on the rankings generated by applying these methods, the use of a voting procedure to aggregate the opinions of the individuals in a decision-making group is proposed. Applying the quartiles voting procedure was conducted in this context and proved to be very useful in solving this type of problem.

The usefulness of the model was demonstrated by using a hypothetical application that was quite compatible with the real-world problem faced by the organisation. By combining the results from the individual analysis of the PROMETHEE II method with the voting by quartiles procedure, allowed individual preferences to be aggregated into a result that was representative of the group, and produced a ranking of suppliers for one of the type of services used by the company. The results were very satisfactory, demonstrating that it is possible to apply the model to a context featuring additional DMs and alternatives. In addition, the company can standardise the scales used in each evaluation, which would ensure more stability for intra-criteria reviews.

There is also the opportunity to document the entire assessment process, thus enabling the company to identify which agent performed the evaluation and why a particular alternative attained its performance. This procedure would bring more transparency to the supplier selection process and to the requirements demanded by the organisation's shareholders and would discourage the company's employees to engage on incorrect behaviours.

As to future lines of research, we suggest improving the model by including the ability to identify and classify the more critical goods and services demanded by the company and by enabling different approaches to be taken for different classes of necessary items. We also propose to insert the classification problematic into the problem, wherein the results of the analysis would include classifying the alternatives that were approved and disapproved. 


\section{References}

Almeida, A.T., Morais, D.C., Costa, A.P., Alencar, L.H. \& Daher, S.F., 2012, Decisão em grupo e negociação: Métodos e aplicações, Atlas, São Paulo.

Amid, A., Ghodsypour, S.H. \& O'Brien, C., 2009, 'A weighted additive fuzzy multiobjective model for the supplier selection problem under price breaks in a supply Chain', International Journal of Production Economics 121(2), 323-332. https://doi.org/10.1016/j.ijpe.2007.02.040

Bai, C. \& Sarkis, J., 2010, 'Integrating sustainability into supplier selection with grey system and rough set methodologies', International Journal of Production Economics 124(1), 252-264. https://doi.org/10.1016/j.ijpe.2009.11.023

Brans, J.P., Macharis, C., Kunsch, P.L., Chevalier, A. \& Schwaninger, M., 1998 'Combining multicriteria decision aid and system dynamics for the control of socio-economic processes', European Journal of Operational Research 109(2) socio-economic processes', European Journal of Operational
428-441. https://doi.org/10.1016/S0377-2217(98)00068-X

Brans, J.P. \& Mareschal, B., 2005, Multiple criteria decision analysis: State of the art surveys, Springer, New York.

Brans, J.P. \& Vincke, P.H., 1985, 'A preference ranking organization method, the PROMETHEE method for MCDM', Management Science 31, 647-656. https://doi. org/10.1287/mnsc.31.6.647

Brans, J.P., Vincke, P., Mareschal, B., 1986, 'How to select and how to rank projects: The Promethee method', European Journal of Operational Research 24(2), 228-238. https://doi.org/10.1016/0377-2217(86)90044-5

Chai, J., Liu, J.N.K. \& Ngai, E.W.T., 2013, 'Application of decision-making techniques in supplier selection: A systematic review of the literature', Expert Systems with Applications 40(10), 3872-3885. https://doi.org/10.1016/j.eswa.2012.12.040

Chai, J. \& Ngai, E.W.T., 2015, 'Multi-perspective strategic supplier selection in uncertain environments', International Journal of Production Economics 166, 215-225. https://doi.org/10.1016/j.ijpe.2014.09.035

Chen, H, Chou, S., Luu, Q. \& Yu, T., 2016, 'A fuzzy MCDM approach for green supplier selection from the economic and environmental aspects', Mathematical Problems in Engineering 8097386, $10 \mathrm{p}$.

Dobos, I. \& Vorosmarthy, G., 2014, 'Green supplier selection and evaluation using DEA-type composite indicators', International Journal of Production Economics DEA-type composite indicators', International Journal of
157, 273-278. https://doi.org/10.1016/j.ijpe.2014.09.026

Ekici, A., 2013, 'An improved model for supplier selection under capacity constrain and multiple criteria', International Journal of Production Economics 141(2) 574-581. https://doi.org/10.1016/j.ijpe.2012.09.013

Favardin, P., Lepelley, D. \& Serais, J., 2002, 'Borda rule, Copeland method and strategic manipulation', Review of Economic Design 7(2), 213-228. https://doi. org/10.1007/s100580200073

Hatami-Marbini, A. \& Tavana, M., 2011, 'An extension of the ELECTRE I method for group decision-making under a fuzzy environment', Omega 39(4), 373-386. https://doi.org/10.1016/j.omega.2010.09.001

Ho, W., Xu, X. \& Dey, P.K., 2010, 'Multi-criteria decision-making approaches for supplie evaluation and selection: A literature review', European Journal of Operationa Research 202(1), 16-24. https://doi.org/10.1016/j.ejor.2009.05.009

Kahraman, C., Cebeci, U. \& Ulukan, Z. 2003, 'Multi-criteria supplier selection using Fuzzy AHP', Logistics Information Management 16(6), 382-394. https://doi. org/10.1108/09576050310503367

Kar, A.K., 2014, 'Revisiting the supplier selection problem: An integrated approach for group decision support', Expert Systems with Application 41(6), 2762-2771. https://doi.org/10.1016/j.eswa.2013.10.009
Kefer, P., Milanovic, D.D., Misita, M. \& Zunjic, A., 2016, 'Fuzzy multicriteria ABC supplier classification in the global supply chain', Mathematical Problems in Engineering 9139483, $11 \mathrm{p}$.

Ku, C., Chang, C. \& Ho, H., 2010, 'Global supplier selection using fuzzy analytic hierarchy process and fuzzy goal programming', Quality and Quantity 44(4), 623-640. https://doi.org/10.1007/s11135-009-9223-1

Li, G.D., Yamaguchi, D. \& Nagai, M., 2008, 'A grey-based rough decision-making approach to supplier selection', International Journal of Advanced Manufacturing Technology 36(9), 1032-1044. https://doi.org/10.1007/s00170-006-0910-y

Liao, Z. \& Rittscher, J., 2007, 'A multi-objective supplier selection model under stochastic demand conditions', International Journal of Production Economics 105(1), 150-159. https://doi.org/10.1016/j.ijpe.2006.03.001

Morais, D.C. \& Almeida, A.T., 2010, 'Water network rehabilitation: A group decisionmaking approach', Water SA 36(4), 487-494. https://doi.org/10.4314/wsa. v36i4.58425

Morais, D.C. \& Almeida, A.T., 2012, 'Group decision making on water resources based on analysis of individual rankings', Omega 40(1), 42-52. https://doi.org/10.1016/j. omega.2011.03.005

Osman, H. \& Demirli, K., 2010, 'A bilinear goal programming model and a modified Benders decomposition algorithm for supply chain reconfiguration and supplier Benders decomposition algorithm for supply chain reconfiguration and supplier selection', International Journal of Prod
doi.org/10.1016/j.ijpe.2009.10.012

Saen, R.F., 2007, 'A new mathematical approach for supplier selection: Accounting for non-homogeneity is important', Applied Mathematics and Computation 185, 84-95. https://doi.org/10.1016/j.amc.2006.07.071

Sanayei, A., Mousavi, S. \& Yazdankhah, A., 2010, 'Group decision making process for supplier selection with VIKOR under fuzzy environment', Expert Systems with Applications 37(1), 24-30. https://doi.org/10.1016/j.eswa.2009.04.063

Sarkis, J. \& Dhavale, D.G., 2015, 'Supplier selection for sustainable operations: A triple-bottom-line approach using a Bayesian framework', International Journal of Production Economics 166, 177-191. https://doi.org/10.1016/j.ijpe.2014.11.007

Schramm, F. \& Morais, D.C., 2012, 'Decision support model for selecting and evaluating suppliers in the construction industry', Pesquisa Operacional 32 643-662. https://doi.org/10.1590/S0101-74382012005000020

Scott, J., Ho, W., Dey, P.K. \& Talluri, S., 2015, 'A decision support system for supplier selection and order allocation in stochastic, multi-stakeholder and multi-criteria environments', International Journal of Production Economics 166, 226-237. https://doi.org/10.1016/j.ijpe.2014.11.008

Sanayei, A., Mousavi, S. \& Yazdankhah, A., 2010, 'Group decision making process for supplier selection with VIKOR under fuzzy environment', Expert Systems with Applications 37(1), 24-30. https://doi.org/10.1016/j.eswa.2009.04.063

Sevkli, M., Koh, L.C.S., Zaim, S., Demirbag, M. \& Tatoglu, E., 2008, 'Hybrid analytical hierarchy process model for supplier selection', Industrial Management and Data Systems 108(1), 122-142. https://doi.org/10.1108/02635570810844124

Vincke, P., 1992, Multicriteria decision aid, Wiley, New York.

Vinodh, S., Ramiya, R.A. \& Gautham, S.G., 2011, 'Application of fuzzy analytic network process for supplier selection in a manufacturing organization', Expert Systems with Applications 38(1), 272-280. https://doi.org/10.1016/j.eswa.2010.06.057

Wu, D., 2009, 'Supplier selection in a fuzzy group setting: A method using grey related analysis and Dempster-Shafer theory', Expert Systems with Applications 36(5), 8892-8899. https://doi.org/10.1016/j.eswa.2008.11.010

Wu, D.D., Zhang, Y., Wu, D. \& Olson, D., 2010, 'Fuzzy multi-objective programming for supplier selection and risk modeling: A possibility approach', European Journal of Operational Research 200(3), 774-787. https://doi.org/10.1016/j.ejor.2009.01.026 